\title{
Long term impact of wind power generation in the Iberian day-ahead electricity market price
}

\author{
Adelino J.C. Pereira ${ }^{a}$, João Tomé Saraiva ${ }^{\text {b,* }}$ \\ a Departamento de Engenharia Electrotécnica, Instituto Superior de Engenharia de Coimbra, Rua Pedro Nunes, 3030-199 Coimbra, Portugal \\ ${ }^{\mathrm{b}}$ INESC Porto and Departamento de Engenharia Electrotécnica e Computadores, Faculdade de Engenharia da Universidade do Porto, Campus da FEUP, Rua \\ Dr. Roberto Frias, 4200-465 Porto, Portugal
}

\section{A R T I C L E I N F O}

\section{Article history:}

Received 4 February 2013

Received in revised form 1 April 2013

Accepted 14 April 2013

Available online 11 May 2013

\section{Keywords:}

Electricity markets

Wind power

Long term impact

Electricity price

System Dynamics model

Iberian electricity market

\begin{abstract}
A B S T R A C T
The Iberian power systems went through important changes at the legal, regulatory and organizational levels in the last 20 years. One of the most relevant ones was the increasing penetration of distributed generation, namely wind parks, together with the development of the common market involving Portugal and Spain. In Portugal, distributed generation is paid using feed in tariffs while in Spain it can choose between receiving a regulated feed in tariff or the market price plus a participation prize. The feed in scheme is now under discussion since it is argued that it represents an excessive cost that is internalized in the end user tariffs. However, this discussion is frequently conducted without complete knowledge of the real impact of wind power on the electricity market price, since it contributes to reduce the demand on the market thus inducing a price reduction. To clarify these issues we used a long term System Dynamics based model already reported in a previous publication to estimate the long term evolution of the market price. This model was applied to the Iberian generation system using different shares of wind power capacity to quantify the impact of wind power on the day-ahead electricity market price.
\end{abstract}

(ㄷ) 2013 Elsevier Ltd. All rights reserved.

\section{Introduction}

The Iberian power system has been submitted to important changes at the legal, regulatory and organizational levels in recent years. In Portugal, the private power companies were nationalized in 1975 leading to the creation of a vertically integrated company owning all generation and transmission assets and the vast majority of distribution. This structure started to change in 1988 when it was passed new legislation to induce investments in distributed generation as a way to increase the use of endogenous resources. These included small hydro stations with installed capacity below $10 \mathrm{MVA}$, all other renewable stations and cogeneration installations leading to what started to be called as Special Regime Generation, SRG. These stations were paid feed-in tariffs that, at the time, corresponded to the tariff paid by end users connected at the voltage level immediately above the connection level of each SRG station. Later on, this tariff scheme was changed so that SRG stations are currently paid according to an avoid cost scheme that includes three terms as follows: investment and operation costs regarding

\footnotetext{
* Corresponding author. Tel.: +351 22 2094230; fax: +351 222094150.

E-mail addresses: ajcp@isec.pt (A.J.C. Pereira), jsaraiva@fe.up.pt (J.T. Saraiva).
}

the costs of the so-called reference thermal station, and environmental costs considering the avoided $\mathrm{CO}_{2}$ emissions. This ultimately means that the tariffs paid to SRG generation depend on their technology in the sense that renewable stations (for instance solar and wind stations) are paid larger tariffs when compared to some cogeneration thermal stations, given the $\mathrm{CO} 2$ avoided emissions term. Later on, in 1995 the sector was reorganized in a public driven system structured in terms of long term contracts established between generation entities and the System Operator, on one side, and between the System Operator and distribution companies, on the other. The legislation of 1995 also considered a market sector including eligible clients and generation agents acting freely in the market and paying access tariffs to use the transmission and distribution networks.

Meanwhile, the Spanish system was structured in terms of concessions awarded to several companies that owned assets both in generation and distribution. This started to change in 1995 with the publication of new legislation similar to the one passed in Portugal in the same year and according to which it was created the regulatory agency for the electricity sector. By the end of 1997 this legislation was substituted by a new electricity law that organized the system in four main activities: generation (grouped in ordinary and special regime), transmission, distribution and retailing. It also 
created the Market Operator managing the day-ahead and the intraday markets and the Transmission System Operator, TSO, having the concession of the transmission network and the responsibility of operating and controlling the system. Regarding Spain, SRG stations can choose between receiving a feed-in tariff in a similar way to what occurs in Portugal or bidding in the dayahead market receiving the clearing market price plus a prize in order to induce the increase of the market liquidity and the number of participating agents.

In 2001 the two systems started to move towards a deeper integration with the signature of a memorandum between the Portuguese and the Spanish governments in order to create the Iberian Electricity Market, MIBEL. This market would include the possibility of bidding in the day-ahead common market as well as establishing bilateral contracts together with several types of financial mechanisms. The common bilateral contract trading mechanism started operating in 2006 and the common day-ahead market started in the 1 st of July 2007 as an extension of the already existing Spanish dayahead market. In the first years of operation the electricity prices in the two countries were different in a large number of hours due to the application of market splitting to solve congestion problems in the interconnections (more than $80 \%$ of the trading hours in 2007 and 2008) but since then the two markets are more strongly coupled and the application of market splitting is now much less frequent (less than 15\% of the trading hours in 2011 and 2012).

Regarding the generation mix, both countries were very successful in increasing the amount of renewables and this corresponded to a strategic policy adopted by successive governments as a way to use more intensively endogenous resources, to enlarge the energetic independency of the two countries and also to develop new industrial activities thus creating new jobs. By the end of 2010, wind power reached what can be termed as a mature state having an installed capacity of 3705 MW out of 17,995 MW in Portugal (20.6\%) and of 19,710 MW out of 98,687 MW in Spain (20.0\%).

As mentioned above, in Portugal SRG generation is paid by pure feed-in tariffs. In some years, namely wet years in which the hydro stations have a larger contribution to supply the demand, the value of the feed-in tariffs gets well above the electricity market price. The difference between these two values corresponds to the over costs of the SRG generation that are socialized among the consumers. In recent years these over costs started to be questioned given the large involved amounts. This discussion is still going on in Portugal and sometimes it is conducted without having complete knowledge of the values that are involved as well as of the impact of renewables, and particularly wind parks, in the market price. In fact, due to SRG generation, the liquid demand traded in the market gets reduced, thus contributing to reduce the market price itself. Apart from this effect, coal and CCGT thermal plants are now much less used than some years ago and when they are in operation the market price is more reduced than before. This means that the profitability of these stations is now more reduced so that the introduction of a specific capacity tariff is currently under discussion.

This evolution and the impact of the SRG installed capacity increase both in Portugal and Spain strongly illustrates the need for adequate regulation in the electricity sector as it is described for instance in Ref. [1]. As new technologies as wind and PV stations get more mature, it is clear that feed in subsidized tariffs should start to be reduced reflecting the reduction of their investment costs. If these adaptations are not considered then more traditional stations, namely thermal ones, will be operating during more reduced periods and the presence of inframarginal technologies reduces the market price thus reducing the revenues of these stations when they are in operation. This can contribute to reduce the investments on new thermal capacity. In order to reduce this risk some countries created specific capacity payments or capacity markets, or designed particular tariff systems for thermal technologies as described in Ref. [2].

Given this framework, this paper reports the research that was developed to investigate and to quantify the long term impact of wind power on the market price as a contribution of the University and research centers to turn this debate more technically sounded and rational. The tool used in the simulations was the long term generation expansion model detailed in Ref. [3] and based on System Dynamics to represent the long term evolution of the generation system and to estimate the evolution of the electricity market price. Using this model we conducted a number of simulations using publicly available data from the Iberian generation/demand system, namely considering the complete absence of wind power as well as different shares of wind installed capacity in order to get insight on the evolution of the market price. Having in mind these general ideas and objectives, this paper is structured as follows. After this Introduction, Section 2 further details the generation mix in Portugal and in Spain as well as the use of the available technologies to supply the demand and the corresponding prices. Section 3 briefly summarizes the main drivers that have been guiding generation expansion models in recent years and Section 4 describes the System Dynamics long term model used in this paper. This will be an abbreviated description since we are profiting from the model fully detailed in Ref. [3]. This model was then run using data from the Iberian system and the results of the simulations are reported and discussed in Section 5. Finally, the most relevant conclusions are drawn in Section 6.

\section{Iberian electricity market and special regime generation}

\subsection{Evolution of the Portuguese power system}

Since the publication of the electricity law back in 1995, the Portuguese power system evolved a lot due to several legal changes. According to that law, the existing vertical company, EDP, was structured in a generation, a transmission and a distribution companies. Then, in 1997 EDP started to be privatized and in 2000 the transmission activity was separated originating the Portuguese Transmission System Operator, REN SA, in charge of the operation of the power system and having the concession of the transmission network. Soon after this organizational change, it was signed a memorandum with the Spanish government in order to implement a common electricity market and negotiations at different levels started by 2001.

A second major legal mark corresponded to the publication of a new electricity law in 2006, Law 29/2006 of 15th February. This law extended eligibility to all consumers and organized generation in normal and special regimes in the sense that the generation facilities in this second group are paid according to subsidized feed-in tariffs. This involves renewables (namely wind parks and PV stations), hydro stations under $10 \mathrm{MVA}$ and cogeneration facilities. In fact, this subsidizing scheme dates back to 1988 and it was very successful in inducing new investments. From a commercial point of view, normal regime generators and the demand can bid in the pool market or establish bilateral contracts to sell/buy electricity.

By the end of 2010 the installed capacity corresponded to 17,995 MW, grouped as follows:

- normal regime - 12,060 MW including $4578 \mathrm{MW}$ in hydro stations (2290 MW in run of river and $2288 \mathrm{MW}$ in reservoirs) and $7482 \mathrm{MW}$ in thermal stations (coal stations - $1776 \mathrm{MW}$, fuel stations - $1476 \mathrm{MW}$, fuel/gas stations - $236 \mathrm{MW}$, gasoil $165 \mathrm{MW}$ and combined cycles - $3829 \mathrm{MW}$ );

- special regime - 5935 MW. This includes 1698 MW in cogeneration stations, $410 \mathrm{MW}$ in small hydro stations, $3705 \mathrm{MW}$ in wind parks and $122 \mathrm{MW}$ in PV stations. 
The Regulatory Agency, ERSE, was created in 1997 and originally it was responsible for the regulation of the electricity sector but its scope was extended to the gas sector in 2004. The tariff system was approved in 1998 and was used for the first time in the first regulatory period from 1999 to 2001. The Tariff Code comprises an additive tariff system organized in terms of an Access Tariff to be paid by all clients, free or regulated ones. The Access Tariff includes the Tariff for the Global Use of the System (namely paying the costs of the control center, the subsidies to the SRG and the costs of ancillary services), the Tariff for the Use of the Transmission Network (including tariffs for EHV and HV networks) and the Tariff for the Use of the Distribution Network (including tariffs for HV, MV and LV networks). Then, the final end user tariff resulting of the addition of the Access Tariff plus the regulated Generation and Retailing Tariffs is paid by regulated clients. Free clients pay the Access Tariff plus non-regulated generation and retailing terms. In 2010, the annual demand corresponded to $52,204 \mathrm{GWh}$ and it was supplied by hydro stations, $28 \%$, coal stations, $13 \%$, combined cycles, $20 \%$, and special regime generation, $34 \%$, namely wind parks with a share of $17 \%$. The import share corresponded to 5\% and the peak demand was $9403 \mathrm{MW}$ at January 11th.

Regarding eligibility, full eligibility was achieved by July 2007. By December 2010, the number of clients in the free market was 357,360 out of 6,000,000 clients, having an annual demand of 18,800 GWh, that is about $36 \%$ of the annual demand. During December 2010 there were about 6950 new clients in the free market, from which 6060 corresponded to changes from the regulated system and 890 corresponded to newly connected clients. Finally, in December 2010, 595 clients changed of the supplier inside the free market.

\subsection{Evolution of the Spanish power system}

As mentioned in Section 1, the Spanish system started to be restructured in 1995 and new legislation was passed by the end of 1997 organizing the system in four main activities: generation, transmission, distribution and retailing. Generation was structured in normal regime (biding in the market or establishing bilateral contracts) and Special Regime, SRG. In this case, SRG can choose receiving a feed-in tariff or biding in the daily market and receiving the market price plus a participation prize. Regarding the end of 2010 the total installed capacity was 98,687 MW split as follows:

- normal regime - 64,813 MW. This includes 17,561 MW of hydro stations, $7777 \mathrm{MW}$ in nuclear stations and 39,475 MW in conventional thermal stations (coal stations - 11,380 MW, fuel/ gas stations - $2860 \mathrm{MW}$ and combined cycles - 25,235 MW);

- special regime - 33,874 MW. This includes $2035 \mathrm{MW}$ in small hydro stations, 19,710 MW in wind parks, $4942 \mathrm{MW}$ in other renewable stations and $7187 \mathrm{MW}$ in other non-renewable stations.

The Spanish day-ahead market started its operation in January 1998 and its trading platform also includes six sessions of the intraday market, typically used to trade small quantities of electricity. System operation is under the responsibility of the Spanish TSO, Red Electrica de Espana, that also has the concession of the transmission system. Full eligibility was achieved in 2003 and in 2010 the annual demand reached 260,530 GWh with a peak power of 44,122 MW in January 11 th. In 2010 , the demand was supplied by hydro stations, $14 \%$, nuclear stations, $22 \%$, coal stations, $8 \%$, combined cycles, $23 \%$, fuel/gas stations, $1 \%$, and special regime generation, $32 \%$, with particular emphasis to wind parks with a share of $15 \%$.

\subsection{The common Iberian electricity market}

The first agreement to implement a common electricity market involving Portugal and Spain was signed at the 14th November 2001.
By that time, it was estimated that this market would start operation in 2003. However, reality proved to be far more complex. It was only in 2006 that the common market for bilateral physical and financial trading was launched and in July 2007 started the common day-ahead market as an extension of the pool that was already in operation in Spain since January 1998. The available interconnection capacity between the two countries has been increasing since then to a maximum of $2200 \mathrm{MW}$ although this value can be reduced due to technical constraints inside each country under specific operational conditions.

The operation planning of the Portuguese/Spanish system involves a day ahead market that accepts buying and selling bids to the next day $24 \mathrm{~h}$ trading periods. Then, these schedules together with bilateral contracts are validated by the two TSO's checking the limits on the interconnection lines in the first place. If these limits are violated as a result of the cleared quantities, then market splitting is used leading to different prices in Portugal and in Spain. In a second phase, the limits of branches of the transmission system inside each country are checked by each TSO. If internal congestion arises, then incremental/decremental bids submitted by generators are used to address it. After obtaining a first feasible scheduled, each TSO runs a market to assign up and down secondary reserve followed by a specific market to contract tertiary reserve. The first session of the intra-day market entirely covering the next day is started at 20.00 each day. As mentioned before, there are currently 6 sessions of the intra-day market at 20.00 of the previous day, at 0.00 , at 4.00 , at 8.00 , at 12.00 and at 16.00 of the operation day. Most of the energy, above $85 \%$, is traded in the day-ahead market. Figs. 1 and 2 indicate the evolution of the monthly traded energy and of the monthly average prices in the Portuguese and Spanish areas for 2008 and 2011.

As it is clear from these graphs, the prices in the two operation zones have been converging along these years. In 2008 the prices were different in the two countries in more than $80 \%$ of the trading hours, that is, in these periods the market splitting mechanism was activated. More recently this percentage declined to less than $15 \%$ in 2011. This is due to the recent installation of new CCGT stations in Portugal, to the commissioning of two new $400 \mathrm{kV}$ interconnection lines increasing the interconnection capacity and also to the reduction of the demand visible when going from Fig. 1 to Fig. 2 due to the ongoing economic crisis affecting the two countries.

\section{Brief literature review in generation expansion planning models}

Generation Expansion Planning, GEP, models changed in view of the restructuring of the power sector that was implemented in several countries and geographic areas. This change of paradigm is well documented in Refs. [4,5] considering there are now several competing generation agents, the generation activity is now more risky and the simulation models should internalize uncertainties affecting several parameters.

Prior to the introduction of competition, GEP was developed in a centralized way and most GEP models were integrated with the expansion planning of transmission networks. The resulting problems were very complex and large and so several publications as $[6,7]$ detail the use of decomposition approaches as for instance Benders cuts. Under the traditional centralized paradigm, some models already recognized that there were several criteria that could be addressed, as for instance [8]. On the other hand, in several approaches the decision variables correspond to integer variables representing the number of power stations of each technology to be commissioned in each period of the planning horizon leading to mixed integer optimization problems as the model in Ref. [8]. More recently, the integer nature of this problem has been addressed using metaheuristic techniques as genetic algorithms [9], simulated annealing [10] and ant colonies [11]. 


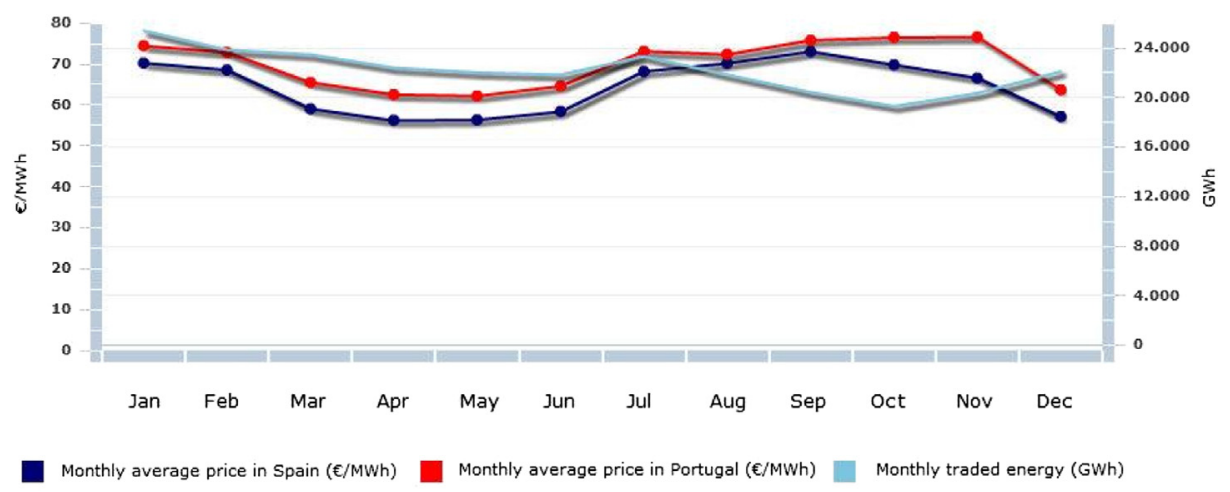

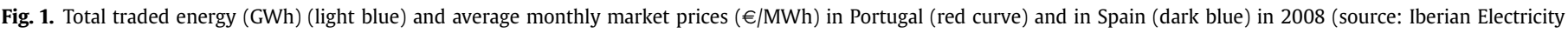
Market Operator, www.omel.es). (For interpretation of the references to colour in this figure legend, the reader is referred to the web version of this article.)

With the advent of restructuring, generation and transmission activities were separated and in the generation subsector there are now several competing agents that bid in the day-ahead markets or establish bilateral contracts. In any case, GEP exercises are now conducted inside each generation agent that should consider the possible reactions of its competitors together with uncertainties affecting fuel prices and construction costs, while getting long term estimates of the evolution of the demand and of the electricity market price. Under this new paradigm [12], describes a two-step approach in which generation agents prepare individual expansion plans that are then submitted to a coordination entity to check for the adequacy of the global generation system to meet the demand. On the other hand, the model described in Ref. [13] uses Dynamic Stochastic Programming together with discrete Markov Chains to handle the demand uncertainty.

Finally, in recent years System Dynamic models [14] are adopted by an increasing number of publications to capture the long term characteristics of electricity markets and the dependencies and interactions among several variables. In this scope [15-18], describe the application of these concepts to several power systems, namely to plan the expansion of the generation system of New Zealand till 2050 [18].

\section{Long term model of the generation system using System Dynamics}

\subsection{Overview of the long term model}

The developed long term planning model incorporates three main modules - a long term dynamic model, a mixed integer optimization model used by each Generation Agent, GENCO, to build expansion plans and a coordination analysis to check a number of global system constraints. These three modules are activated in sequence leading to an iterative process until a convergence condition holds. In the first place, the long term dynamic model is used to provide estimates for the long term evolution of the demand, of the electricity market price and of the capacity factors of the generation technologies used in the planning exercise. These estimates are then used by each GENCO to build its own expansion plan for the entire horizon using a mixed integer formulation. Then, using these plans, a number of system constraints and global indices are checked in order to evaluate the quality of the overall expansion plan in terms of meeting the demand and of complying with long term energy policy objectives. If any of these constraints or global indices are violated or if in two successive iterations the plans obtained by the GENCO's differ, then the process returns to the dynamic model that is run again to update the mentioned long term estimates. Sections $4.2-4.4$ will now give further details on each of these modules.

\subsection{Individual maximization of the profits}

In the first place, let us admit that each GENCO knows estimates for the demand evolution along the horizon, as well as for the electricity price and for the capacity factor of each technology. These estimates correspond either to initial values provided by the planner in case the first iteration is run or are provided by the long term dynamic model in subsequent iterations. Using this information each GENCO aims at identifying the most adequate expansion plan that maximizes the estimated profit to be obtained

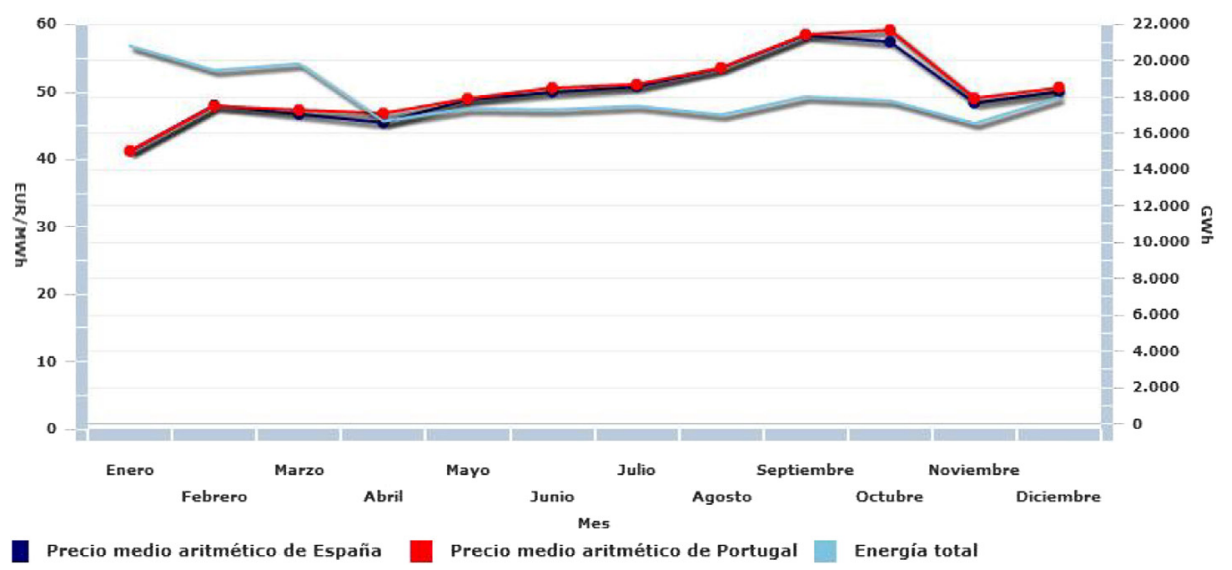

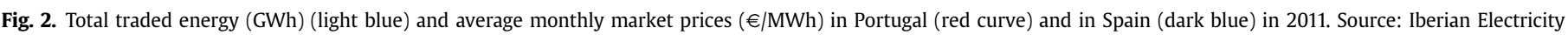
Market Operator, www.omel.es. (For interpretation of the references to colour in this figure legend, the reader is referred to the web version of this article.) 
along the horizon. This plan is built by selecting among the candidate technologies and available capacities that can be installed, the most adequate ones while conveniently locating their commissioning year in the planning horizon. Given there is a number of candidate technologies and for each of them there is a finite number of admissible capacities that can be installed, the optimization problem to be solved by each GENCO is a mixed integer one and it can be formulated by (1-7). In this formulation the decision variable $X_{t}^{i j}$ represents the new capacity of technology $j$ to be commissioned in stage $t$ by Genco $i$.

$$
\begin{aligned}
\max z= & \sum_{t=1}^{T}\left[\sum_{j=1}^{M} \pi^{t} \cdot C C_{t}^{i j} \cdot \Delta t \cdot \alpha_{t}^{i j}+\sum_{j=1}^{M} P_{\mathrm{cap}}^{j} \cdot C C_{t}^{i j} \cdot\left(1-\alpha_{t}^{i j}\right)\right. \\
& \left.-\sum_{j=1}^{M} \operatorname{Cinv}_{t}^{j} \cdot X_{t}^{i j}-\sum_{j=1}^{M} \operatorname{Cop}_{t}^{j} \cdot C C_{t}^{i j} \cdot \Delta t \cdot \alpha_{t}^{i j}\right]
\end{aligned}
$$

$\operatorname{subj} X_{t}^{i j} \leq \operatorname{MIC}_{t}^{i j}$ for each $t$ and each $j$

$\sum_{j=1}^{M} X_{t}^{i j} \leq \operatorname{MIC}_{t}^{i}$ for each $t$

$\sum_{j=1}^{M} X_{t}^{i j} \cdot \operatorname{Cinv}_{t}^{j} \leq \mathrm{MXINV}_{t}^{i}$ for each $t$

$\sum_{t=1}^{T} \sum_{j=1}^{M} X_{t}^{i j} \cdot \operatorname{Cinv}_{t}^{j} \leq \mathrm{MXINV}^{i}$

$C C_{t}^{i j}=C C_{t-1}^{i j}+X_{t}^{i j}$ for each $t$, for each $j$

$t=1, \ldots, T ; i=1, \ldots, N ; j=1, \ldots, M$

In this formulation:

\begin{tabular}{ll}
\hline$t$ & -stage in the planning horizon; \\
$T$ & -number of stages in the planning horizon; \\
$\Delta t$ & -duration in hours of each stage in the planning horizon; \\
$j$ & -type of candidate expansion technology; \\
$M$ & -number of candidate technologies; \\
$i$ & -index associated to a particular GENCO; \\
$N$ & -number of GENCO's; \\
$\pi^{t}$ & -electricity price in stage $t,(€ /$ MWh); \\
$P_{\text {cap }}^{j}$ & -capacity payment set for technology $j,(€ /$ MW); \\
$\alpha_{t}^{i j}$ & -capacity factor in stage $t$ for GENCO $i$ and technology $j$, \\
$C_{\text {inv }}^{j}$ & (percentage); \\
opp $_{t}^{j}$ & -investment cost for technology $j$ at stage $t,(€ /$ MW); \\
$C C_{t}^{i j}$ & -variable operation and maintenance cost for technology \\
$X_{t}^{i, j}$ & $j$ at stage $t,(€ /$ MWh); \\
MIC $_{t}^{i j}$ & -cumulative capacity installed in stage $t$ for GENCO $i,(\mathrm{MW}) ;$ \\
MIC $_{t}^{i}$ & -capacity addition of technology $j$ in stage $t$ by GENCO $i,(\mathrm{MW}) ;$ \\
MXINV $_{t}^{i}$ & -upper bound set for the installed capacity of technology $j$ in \\
MXINV $^{i}$ & stage $t$ by GENCO $i,($ MW); \\
& -maximum capacity that can be installed in stage $t$ by GENCO \\
& -maximum value specified for the investment of GENCO $i$ at \\
& stage $t,(€) ;$
\end{tabular}

This formulation is different from the one described in Ref. [3] because it now includes a capacity payment term that can be used to investigate the impact of introducing such payment in the investment decisions of each GENCO, as it will be illustrated in
Section 5. Regarding the objective function (1), it is given by the difference of the incomes and the costs along the planning horizon, assuming that all values are brought to the initial period using an adequate actualization rate. In (1) the first term represents the revenues obtained by GENCO $i$ from selling electricity at the market price $\pi^{t}$ in each period $t$ of the horizon. For each period $t$, this revenue is obtained multiplying the electricity price $\pi^{t}$ by the installed capacity of each technology $j$, by the capacity factor of that technology and by the duration of each period. The second term corresponds to the capacity payment. This payment is computed multiplying the capacity payment term $P_{\text {cap }}^{j}$ set for technology $j$ by the installed capacity of that technology in each period $t$ and by the percentage of hours in each period during which that capacity is not in operation. The capacity term $P_{\text {cap }}^{j}$ should be set externally and in someway it corresponds to a market design decision to be adopted by the regulatory agency of some other state board. Of course, individual GENCO's can conduct sensitivity analysis in order to investigate the impact that different values of $P_{\text {cap }}^{j}$ have in their expansion plans. Regarding the costs in (1), the third term represents the investment cost associated with each candidate technology $j$ in each period of the horizon and the fourth term models the operation and maintenance costs along the horizon. The objective function (1) is then subjected to constraints associated with:

- limits set for new installed capacity of technology $j$ in each period (2);

- limits for the entire new installed capacity in each period for all candidate technologies (3). These limits as well as the ones used in (2) can be set individually by each GENCO or can correspond to a regulatory decision, for instance, as way to prevent market power or to internalize energy policy objectives;

- limits on the investment cost admissible for each period $t$ (4) and for entire set of periods in the planning horizon (5).

Constraints (6) for each period $t$ and each candidate technology $j$ are only used to update the cumulative installed capacity of GENCO $i$ as the planning horizon develops. As indicated before, this corresponds to a mixed integer problem given that for each candidate technology there is typically a number of normalized values for the capacity that it is possible to install. The feasible values of these capacities as well as the corresponding operation, investment and maintenance costs have to be supplied by the planner when starting the planning exercise. Finally, as mentioned above to formulate this problem it is necessary to input estimates for the electricity price and for the capacity factors of each technology. In the first iteration these values will be specified by the planner and from that point onwards the long term dynamic model is then in charge of building new estimates for these variables, namely internalizing the long term impact of the investments commissioned by each GENCO.

Given the mixed integer nature of this problem, a Genetic Algorithm was used to solve it. As for other applications of Genetic Algorithms, this includes an initialization step, an evaluation step, a convergence check and the application of the genetic operators. Regarding the initialization step, an initial population was randomly created considering the candidate technologies and the possible capacities for each of them. In the developed approach, an individual in the population is coded as a string that indicates for each technology and for each period in the horizon, the number of such stations that start operation in that period. Then, each individual in the current population is evaluated computing the value of the objective function (1). Apart from that, the constraints (2)(6) are also checked and if any of them is violated, then negative penalty terms are included in (1) signalling that the individual 
under analysis is of poor quality. Once all individuals in the current population are evaluated, convergence is checked computing the average value and the standard deviation of the fitness function of all individuals in the population. The convergence condition corresponds to the conjunction of: the average value of the fitness function is sufficiently stable for a pre specified number of iterations, the standard deviation is smaller than a specified threshold and the fitness function of the best individual (the one having the largest fitness value) didn't change more than a specified threshold for a pre specified number of iterations. If convergence was not yet obtained, the individuals in the current population are subjected to the genetic operators of selection, cross-over and mutation in order to generate a new population. Once this step is finished, the individuals in the new population are evaluated thus starting a new iteration. Finally, in order to prevent a premature stop of the algorithm, a minimum number of iterations are always run even though the convergence criteria are already met. When the algorithm stops the best individual, the one associated with the largest value of the fitness function, is then used as the best expansion plan identified for GENCO $i$.

\subsection{Coordination analysis}

Once all GENCO's solved their individual profit maximization problems, as detailed in Section 4.2, values for the $X_{t}^{i, j}$ variables for every GENCO $i$, for every candidate technology $j$ and for every period $t$ in the horizon are obtained. This information together with the generation mix in service in the beginning of the exercise and the decommissioning plan that is eventually implemented taking into account the aging of several stations, enables computing a number of indices that are used to evaluate the goodness of the global expansion plan, from different points of view. Although market approaches were adopted in several countries to address operation planning issues, long term expansion activities continue to be closely monitored, namely because it is crucial to ensure the long term ability of the generation system to meet the demand while fulfilling energy policy objectives set by individual countries. As an example, the EU Directive 2003/54/EC establishing common rules to implement the internal electricity market in the EU countries [19] clearly indicates in article 4 that the "member states shall ensure the monitoring of security of supply issues" and continues stating that "this monitoring shall, in particular, cover the supply/demand balance on the national market, the level of future demand and envisaged additional capacity being planned or under construction, and the quality and level of maintenance of the networks, as well as measures to cover peak demand and to deal with shortfalls of one or more suppliers". This article was maintained unchanged in the new EU Directive passed in 2009 on the common rules to the internal electricity market [20]. On the other hand, specific rules to be fulfilled by agents of the sector are often established by national legislations. As an example, the Portuguese Electricity Law passed in February 2006 [21] currently in force enumerates a set of public service obligations that includes the security and the quality of supply and it also states that the government is responsible for defining the share of different energy vectors to generate electricity and for the promotion of the diversification of the primary resources to generate electricity.

In line with these concerns, and also in order to ensure that national energy policy objectives are met, the developed approach includes a module to check a number of global constraints. It is important to clarify that the constraints and the corresponding indices indicated below just correspond to a possible implementation of this module because the approach is flexible to allow considering different sets of global constraints provided they can be evaluated using the outputs of the planning exercise. This means that this module can be easily tailored to what is determined in the specific legislation of different countries, geographical areas or organizations.

In the current expansion planning approach, the global constraints to be checked are the following ones:

- reserve margin - this index is computed by (8) and it corresponds to the surplus of the available installed capacity regarding the peak demand. The computed yearly values of this index are compared with pre set minimum and maximum values as indicated by (9).

$\mathrm{RM}_{t}=\left(\frac{\text { Installed capacity }}{t}-1\right) 100 \%$

$\mathrm{RM}_{t}^{\min } \leq \mathrm{RM}_{t} \leq \mathrm{RM}_{t}^{\max } \quad$ for $t=1, \ldots, T$

- installed capacity limit per technology - as mentioned above national agencies have the responsibility to establish national energy policy objectives that can include, among others, minimum or maximum values for the installed capacity of some specific technologies. Therefore, using the outputs of the individual expansion plans, one can check constraints (10) and/or (11) to evaluate the participation of different technologies or primary resources in the generation mix. In these constraints, $\bar{J}^{\max j}$ and $\bar{J}^{\mathrm{min} j}$ are the maximum and minimum values that can be assumed by the installed capacity of technology $j$ in any period of the planning horizon;

$\sum_{i=1}^{N} X_{t}^{i j} \leq \bar{J}^{\max j} \quad$ for $t=1, \ldots, T$ and $j=1, \ldots, M$

$\sum_{i=1}^{N} X_{t}^{i j} \geq \bar{J}^{\min j} \quad$ for $t=1, \ldots, T$ and $j=1, \ldots, M$

- in order to contribute to increase the competitiveness of the market, to prevent market power and to facilitate the entry of new agents, it is possible to set a value for the maximum share that GENCO $i$ can own regarding the total amount of capacity in the system, (12). In this constraint $C C_{t}^{i}$ and $C C_{t}^{p}$ are the cumulative installed capacity of GENCO's $i$ and $p$ and Perc ${ }^{\text {max }}$ is the maximum percentage of installed capacity that can be owned by an individual GENCO, on each stage of the horizon;

$C C_{t}^{i} \leq \frac{\text { Perc }^{\text {max }}}{100} . \sum_{p=1}^{N} C C_{t}^{p} \quad$ for $t=1, \ldots, T$ and $i=1, \ldots, N$

- finally, using the capacity to be commissioned along the planning horizon, the capacity installed in the beginning of the exercise and the decommissioning plan, together with the demand evolution along the horizon it is possible to compute adequacy indices characterizing the ability of the generation system to cover the demand. One of these indices is the Loss of Load Expectancy, LOLE, expressing the number of hours it is expected that the generation system is unable to supply the demand [22]. After computing this index for every period in the horizon, it is possible to check constraint (13) in terms of the maximum number of hours that it is admitted not to supply the demand. It is important to notice that the Grid Codes of several countries set maximum values for LOLE, LOLE ${ }^{\mathrm{max}}$, that should then be used in the planning exercises in those countries. 


$$
\operatorname{LOLE}_{t} \leq \mathrm{LOLE}^{\mathrm{max}} \quad t=1, \ldots, T
$$

In case some of these global constraints are violated, then the long term dynamic model to be described in Section 4.4 is run again to update the estimates for the electricity prices, for the demand and for the capacity factors of the candidate technologies, along the planning horizon. When activating again the dynamic model, we are now using the installed capacities and the corresponding commissioning years obtained by each GENCO as a result of the solution of their individual profit maximization problems (1-7). When, these estimates are obtained, each GENCO solves again problem (1-7) thus defining an iterative process that finishes when all global constraints are feasible and the plan obtained in two successive iterations does not change.

\subsection{Long term behaviour of electricity prices using System Dynamics}

As mentioned before, the long term model that was adopted to estimate the behaviour of the electricity price, of the demand and of the capacity factors of the candidate generation stations was fully detailed in Ref. [3]. The main modules of this model are indicated in Fig. 3 that represents the casual loop diagram that was implemented to define the interdependencies and interrelations among several variables. Using System Dynamic concepts, this casual loop diagram was implemented using an academic version of the POWERSIM software package [23,24] and was then translated into a set of differential equations solved by numerical methods within this package once an integration time step is specified.

According to Fig. 3, the long term model includes the following main modules:

- Generation model - the lower part of the diagram of Fig. 3 contains the sub models representing different generation technologies. In this case, we considered hydro stations, special regime generation, SRG, and thermal stations (namely nuclear stations, coal, fuel and CCGT's). In any case, this module can be easily adapted in order to consider the technologies that are relevant for the system under analysis. In the case of the Iberian generation system, there is an important share of several types of distributed generation including wind parks, solar systems and cogeneration systems. In Portugal, SRG receive feed-in tariffs while in Spain SRG generation can choose between receiving a regulated tariff or bidding in the daily market and receiving the market price plus a participation prize. In both cases, it is possible to say that there is priority in including the output of these stations in the mix so that in the developed long term planning model we considered all these distributed stations using historical values for the respective capacity factors. For instance, for wind parks we considered an average capacity factor of $25 \%$ that reflects both the availability of the equipments themselves and of the primary resource. The volatility of the wind resource is then included considering that for each time step of the planning exercise it was sampled a particular value for the capacity factor using a stochastic process. Hydro stations were grouped in two sets - run-of-river and reservoirs, and for each of them average capacity factors based on historical data were specified. Then, for each time step, it was sampled a particular value for the capacity factor of the aggregate of run of river stations and another value for the set of reservoirs using stochastic processes. A similar approach was used for nuclear stations having in mind that they typically operate in the base of the load diagram with large capacity factors. Regarding the remaining thermal stations (coal, fuel and CCGT's) typical cost operation curves were specified in function of the capacity factor. In other to represent in a more refined way these thermal stations, we also subdivided coal stations in two groups and CCGT's in another two sets, in order to be able to specify different operation costs for each of them. Then, for each time step, the long term model uses the estimated outputs of the hydro stations, of the nuclear stations and of the SRG stations together with the estimated demand to obtain an estimation of

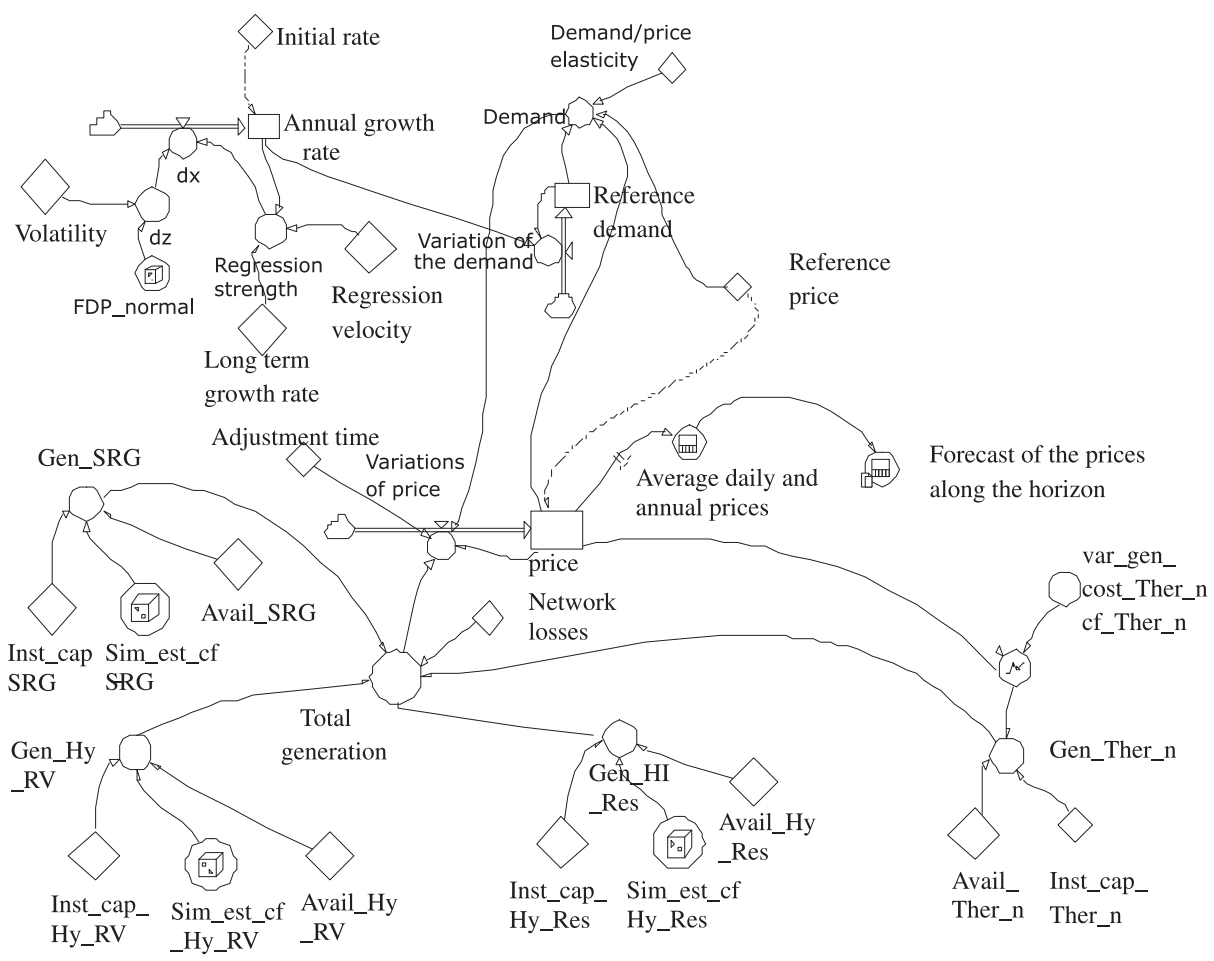

Fig. 3. Casual loop diagram of the long term dynamic model of the electricity market. 
the output of the remaining thermal stations. Then using the specified cost curves for each of the remaining thermal technologies, the mentioned output is allocated to these technologies on the basis of a least cost approach. At the end of this process and for each time step, the capacity factor of each thermal technology as well as the corresponding output is then obtained. It is also important to mention that the total demand is adjusted by a factor larger than 1 (typically in the range from 1.08 to 1.10 ) to internalize transmission and distribution losses. This is represented in the central part of the diagram of Fig. 3;

- Annual load growth rate - another major module corresponds to the estimation of the evolution of the demand annual growth rate. This module is located in the upper left part of the diagram of Fig. 3 and the evolution of this rate was modelled by a Orneisten-Uhlenbeck mean reverting process [16] that uses a reference demand rate, drate $_{0}$, initially specified by the user plus a term that is updated as the simulation evolves and that computes the variation of the annual growth rate regarding this reference value (14). In this expression $\mathrm{d} x$ results from two components as indicated in (15). The first one models the speed of reversion of the demand growth rate to the long term rate, drate $_{L T}$, and it depends on the speed of reversion parameter, $\eta$. Shorter term variations around the long term trend are modelled by the second term in (15) using a Wiener process that depends on the volatility parameter, $\delta$. Both $\eta$ and $\delta$ are specified by the user and in brief, for a fixed $\delta$, larger values for $\eta$ imply that the demand growth rate value returns back to the long term rate more rapidly. For a fixed value for $\eta$, larger values for $\delta$ mean that there are larger shorter term variations of the demand rate, although the long term value keeps unchanged. In (15) $\varepsilon_{t}$ represents a random number sampled from a normal $(0,1)$ distribution for each time step $t$ of the long term simulation;

drate $=$ drate $_{0}+\int_{0}^{T} \mathrm{~d} x . \mathrm{d} t$

$\mathrm{d} x=\eta \cdot\left(\right.$ drate $_{L T}-$ drate $\left._{t}\right) \cdot \Delta_{t}+\varepsilon_{t} \cdot \delta \cdot \sqrt{\Delta t}$

- Demand evolution - having estimated the demand growth rate for each time step of the long term simulation, the corresponding demand evolution is obtained in the module located in the upper central part of the diagram of Fig. 3. In the first place, it is computed a reference demand value for each time step $t$ (16) and then this reference value is adjusted using the elasticity of the demand to the electricity price, $E_{\mathrm{d} \pi}$, using (17). This elasticity parameter is supplied by the user and currently it typically corresponds to a value close to zero, indicating that the demand displays a very inelastic behaviour regarding the price. In these expressions, $\pi^{t}$ and $\pi^{0}$ are the electricity price estimated for period $t$ and the reference price at the departing stage of the long term simulation. This reference price can be set using historical data regarding the behaviour of the market under analysis in recent years;

$d_{\text {ref }, t}=d_{\text {refo }}+\int_{0}^{T}$ drate $_{t} \cdot d_{\text {refo }} \cdot \mathrm{d} t$

$d_{\text {elec }, t}=d_{\text {ref }, t} \cdot\left(\frac{\pi^{t}}{\pi^{0}}\right)^{E_{\mathrm{d} \pi}}$

- Electricity price evolution - finally, the module in the central part of the diagram of Fig. 3 is used to estimate the electricity price in each step of the simulation. In each time step, price variations are computed using (18) using the price at the departing stage of the simulation, $\pi^{0}$, and the balance between the demand and the generation. The reasoning behind the use of this balance is to be able to transmit on the long term a signal to market agents, namely to generation agents, regarding a possible deficit of generation. If that happens, or if the gap between generation and demand reduces, then there is a positive value coming from (19) that is then used in (18) to increase the electricity price. On the long term, this price increase would then induce new generation investments turning them more profitable and attractive. In any case, the information regarding the balance between demand and generation can be smoothed by using the Attenuation Factor, AF, in (19).

$\pi^{t}=\pi^{0}+\int_{0}^{T} \Delta \pi^{t} \cdot \mathrm{d} t$

$\Delta \pi^{t}=\pi^{0}\left(\frac{d_{\text {elec }, t}-G_{\text {total }}}{d_{\text {elec }, t}}\right) \cdot \frac{1}{\mathrm{AF}}$

At this point, it is important to recognize there is a loop involving the demand and the electricity price. This is represented in the diagram of Fig. 3 by the link departing from the price towards the demand node and by the link departing from the demand to the price variation node. This interdependency can also be recognized in expressions (17) and (19). The first one uses the price in step $t$ to obtain the demand in that time step and (19) uses the demand to influence the price variations.

The long term model represented in Fig. 3 is finally translated in a set of differential equations (namely including (14-19)) that are solved inside the POWERSYM academic package [23,24]. Apart from this simulation package, in the developed tool MATLAB was also used to implement the genetic algorithm to solve the individual profit maximization problems $(1-7)$ and to compute the LOLE reliability index and Microsoft Excel was used to interface the remaining modules and to build tables and graphs.

\section{Case study based on the Iberian electricity market}

\subsection{Data and main assumptions}

As mentioned in the Introduction, the main objective of this paper is to evaluate the impact of wind power generation in the price of the MIBEL day-ahead market as well as to illustrate the studies that can be conducted to adequately calibrate the value of a capacity term that can be eventually included in the generators' payment. For this purpose, a number of simulations based on the generation mix of Portugal and Spain were run considering different shares of wind power installed capacity. The results of these simulations are presented in Sections 5.2-5.6 sorted by the increasing value of the installed wind power capacity. Accordingly:

- Section 5.2 - Case 1 - it corresponds to consider the wind power installed capacity at zero;

- Section 5.3 - Case 2 - we considered the wind power installed capacity in 2010 reduced by $50 \%$;

- Section 5.4 - Case 3 - it corresponds to the situation that existed by the end of 2010 ;

- Section 5.5 - Case 4 - we considered the wind power installed capacity in 2010 increased by $25 \%$;

- Section 5.6 - Case 5 - the wind power capacity installed by the end of 2010 was increased by $50 \%$. 
Finally, Section 5.7 illustrates the use of the developed long term expansion model to calibrate the capacity term included in (1), namely to ensure a pre defined profit level for the generation agents.

The basic data that was used and the assumptions that were adopted along the simulations are detailed in the next paragraphs. It is important to mention that the constitution of the generation mix used in these simulations closely mirrors the generation assets of the two countries given the information publicly available in the web sites of the System Operators of Portugal and Spain. However, the authors do not have information about the investment strategies to be followed in the next years by the generation agents nor on the financial resources that each of them admits to invest. Therefore, this type of data was specified by the authors just as a way to illustrate the use of the developed approach. More refined information of this type would obviously be required to run a more realistic study.

In the first place, the generation mix in the Iberian Peninsula by December 2010 is detailed in Table 1. The Portuguese and the Spanish systems had installed capacities of 17,995 and of 98,687 MW and the total demand was 52,204 GWh and 260,530 GWh. Nuclear stations are all located in Spain and the Forced Outage Rates of the thermal stations are also indicated in this Table. These values are then used to compute reliability indices. As mentioned before, nuclear stations were admitted to have a neglectable FOR and regarding SRG units the number of operation hours internalize not only the availability of the primary resource (wind, for instance) but also eventual outage or maintenance periods. It is also important to mention that both coal and CCGT stations were split in two groups so that these technologies can be modelled in a more refined way, namely regarding the value of the operation costs.

In order to turn the simulations more realistic, 6 larger Generation Companies designated as Genco_1 to Genco_6, were considered in the simulations. These companies own the following shares of installed capacity: Genco_1 owns 16.5\%, Genco_2 has $22.0 \%$, Genco_3 has 5.2\%, Genco_4 owns 12.6\%, Genco_5 has 3.7\% and Genco_6 owns $10.0 \%$. Finally, there is a large number of smaller generation agents (namely owning SRG assets, as wind parks, small hydro and cogeneration stations) that were grouped in Genco_7 corresponding to $30 \%$ of the installed capacity.

Apart from the ownership of the generation assets, several other assumptions are enumerated below:

i) Capacity factors of the power stations in the generation mix:

a. nuclear stations - a capacity factor of $85 \%$ with a standard deviation of $5 \%$ was used for these stations;

b. hydro stations - they were divided in two sets, reservoirs and run of river stations, to better represent their

Table 1

Characteristics of the Iberian generation mix.

\begin{tabular}{lcccc}
\hline Technologies & $\begin{array}{l}\text { Installed capacity } \\
\text { in Portugal (MW) }\end{array}$ & $\begin{array}{l}\text { Installed capacity } \\
\text { in Spain (MW) }\end{array}$ & $\begin{array}{l}\text { Total installed } \\
\text { capacity (MW) }\end{array}$ & FOR \\
\hline Nuclear & 0 & 7777 & 7777 & - \\
Coal_1 & 1184 & 7584 & 8768 & 0.02 \\
Coal_2 & 592 & 3796 & 4388 & 0.02 \\
Fuel/gas and gasoil & 1877 & 2860 & 4737 & 0.02 \\
$\quad$ & & & \\
turbines & 2550 & 16,820 & 19,370 & 0.02 \\
CCGT_1 & 1279 & 8415 & 9694 & 0.02 \\
Hydro reservoirs & 2288 & 10,537 & 12,825 & - \\
Hydro run-of-river & 2290 & 7024 & 9314 & - \\
Wind parks & 3705 & 19,710 & 23,415 & - \\
Small hydros & 410 & 2035 & 2445 & - \\
Other renewables & 122 & 4942 & 5064 & - \\
Cogeneration & 1698 & 7187 & 8885 & - \\
\hline
\end{tabular}

characteristics. Based on historical values, an average capacity factor of $20 \%$ for reservoirs and $25 \%$ for run of river together with a standard deviation of $5 \%$ were used for these stations;

c. wind parks and photovoltaic systems - based on historical values, we admitted average capacity factors of $25 \%$ and of $20 \%$ and a standard deviation of $5 \%$;

d. cogeneration and biomass systems - average capacity factors of $45 \%$ and of $55 \%$ were used for these technologies.

ii) Planning horizon, commissioning and decommissioning plans:

a. the duration of the planning horizon was set at 15 years;

b. decommissioning plan - $1500 \mathrm{MW}$ of nuclear groups in year 3,1000 MW of Coal_1 stations in year 4 and 1000 MW in year 8 and finally 1000 MW of CCGT_1 in year 10;

c. commissioning plan - for some types of stations it is usual to open tenders to allocate new capacity. For instance in Portugal this procedure is adopted for hydro stations and for wind parks. As a result, it was considered pointless to include these technologies as candidate ones regarding which the long term expansion problem should take a decision, given that the construction of new hydro's and wind parks in fact depend on administrative procedures. Therefore, we used official data as well information on stations that are currently being built to obtain a commissioning plan for these technologies. For wind parks this plan includes $200 \mathrm{MW}$ per year from year 1 to year 4 and $100 \mathrm{MW}$ from year 5 to year 10 . For photovoltaic systems we admitted $200 \mathrm{MW}$ in year 3,150 MW in year 6 and $200 \mathrm{MW}$ in year 9. Finally, we admitted $500 \mathrm{MW}$ of new hydro capacity in year 6 and $300 \mathrm{MW}$ in year 10;

iii) Demand - in 2010 the total demand of Iberian system was 312.7 TWh. For simulation purposes, this demand was modelled using a load duration curve organized in the following 6 steps - 100\% of the peak power during $5 \%$ of the year, $90 \%$ for $20 \%$ of the year, $80 \%$ for $45 \%$ of the year, $70 \%$ for $65 \%$ of the year, $60 \%$ for $85 \%$ of the year and $50 \%$ of the peak power during $100 \%$. The demand long term rate along the planning horizon was set at $2 \%$ and it was admitted that this rate affects all the steps of the load duration curve in each year, so that its shape remains unchanged. It should be noted that as a result of the dynamic simulation, the yearly demand rate does not remain stable at $2 \%$ but it is affected by the evolution of the fuel and electricity market prices;

iv) Candidate technologies - apart from wind power and hydro stations regarding which specific tender procedures were considered, we admitted that there are three traditional thermal technologies termed as Tech_1, Tech_2 and Tech_3. These three technologies correspond to combined cycle gas plants, to simple cycle gas plants and to coal fire plants and generation companies can choose among them when building their expansion plans. The main characteristics of these three candidate technologies are detailed in Table 2 and were obtained from Ref. [25]. This document provides ranges for generation costs based on data from almost 200 power plants from 17 countries that are members of the Organisation for

Table 2

Characterization of the candidate technologies.

\begin{tabular}{llcclc}
\hline $\begin{array}{l}\text { Type of } \\
\text { technology }\end{array}$ & $\begin{array}{l}\text { Available } \\
\text { capacities } \\
\text { (MW) }\end{array}$ & $\begin{array}{l}\text { Investment } \\
\text { cost }(€ / \mathrm{MW})\end{array}$ & $\begin{array}{l}\text { Fix O\&M cost } \\
(€ / \mathrm{MW} \text { year })\end{array}$ & $\begin{array}{l}\text { Cost of capital } \\
\text { with the loan } \\
(€ / \mathrm{MW} \text { year })\end{array}$ & FOR \\
\hline Tech_1 & 200 or 400 & 650,000 & 7050 & 52380.40 & 0.02 \\
Tech_2 & $\begin{array}{l}\text { 200 or } 300 \\
\text { or } 400\end{array}$ & 500,000 & 6200 & 40230.40 & 0.02 \\
Tech_3 & 200 or 400 & $1,050,000$ & 8600 & 82300.10 & 0.02 \\
\hline
\end{tabular}


Table 3

Data for the System Dynamic simulation.

\begin{tabular}{lllc}
\hline$t_{0}(\% /$ year $)$ & 3 & $D_{\text {ref }}(\mathrm{GWh} /$ year $)$ & 312.700 \\
$t_{L T}(\% /$ year $)$ & 4 & $E_{\mathrm{d} \pi}$ & 0.25 \\
$\eta$ & 0.50 & $T$ (years $)$ & 15 \\
$\delta$ (\%/year) & 0.40 & $\pi^{t 0}(€ / \mathrm{MWh})$ & 55.3 \\
\hline
\end{tabular}

Economic Cooperation and Development, OECD, plus 4 non OECD countries. For these technologies it was specified a construction period after licencing of 3 years for Tech_1 and Tech_3 and of 2 years for Tech_2 and a life time of 30 years. Regarding the operation costs, the respective non linear curves were discretized in a number of segments in function of the capacity factor of each station. Regarding Tech_1 and for illustrative purposes, the operation cost was $15.0 € / \mathrm{MWh}$ when the capacity factor ranges from 0.0 to 0.2 , it was $30.0 € / \mathrm{MWh}$ from 0.2 to 0.4 , it was $40.0 € / \mathrm{MWh}$ from 0.4 to 0.6 , it was $65.0 € / \mathrm{MWh}$ from 0.6 to 0.8 and finally from 0.8 to 1.0 the operation cost was set at $80.0 € / \mathrm{MWh}$.

v) Financial limitations - in order to consider financial limitations of the generation agents and to illustrate the application of the developed Dynamic Model, it was admitted that GENCO's 5 to 7 will not increase their installed capacity. Regarding GENCO's 1 to 4, the following limitations apply:

a. Genco_1 has $1200 \mathrm{M} €$ available for the first 10 years plus $400 \mathrm{M} €$ in the final 5 years;

b. Genco_2 has $500 \mathrm{M} €$ available for the first 5 years, plus $1200 \mathrm{M} €$ for the final 10 years;

c. Genco_3 has $500 \mathrm{M} €$ from year 1 to year 5, plus $500 \mathrm{M} €$ from year 6 to year 10 , plus $500 \mathrm{M} €$ for the final 5 years;

d. Genco_4 has no resources to invest from year 1 to year 3 . From year 4 till year 15 it has $1200 \mathrm{M} €$ available.

vi) Other parameters and constraints - the developed approach requires the specification of other parameters as follows: the minimum yearly reserve margin was set at 30\% and the maximum value for LOLE was set at $2.0 \mathrm{~h} /$ year. To illustrate the incorporation of energy policy objectives, it was considered that in each year of the horizon, each generation agent can not install more than 800 MW of Tech_1, 400 MW of Tech_2 and 400 MW of Tech_3. Finally, the share of any candidate technology regarding the total new installed capacity should not exceed $50 \%$.

vii) Regarding the dynamic simulation, the values used for several parameters mentioned in Section 4.4 are detailed in Table 3.

\subsection{Case 1 - wind power capacity at zero}

In the first place and as a reference situation against which the results of the next simulations are compared, the dynamic model was run admitting that the installed wind power capacity indicated in Table 1 was not considered. This is an extreme case designed to obtain the electricity price evolution based on hydro and on thermal technologies (nuclear, coal, CCGT and cogeneration) and it corresponds to eliminate 23,415 MW of installed capacity and an average of 51.2 TWh, admitting a capacity factor of $25 \%$. This represents $20.1 \%$ of the total installed capacity and $15.9 \%$ of the energy

Table 4

Case 1 - expansion plan for GENCO_1.

\begin{tabular}{llll}
\hline Stage & Tech_1 (MW) & Tech_2 (MW) & Tech_3 (MW) \\
\hline 1 & 400 & 300 & 200 \\
2 & 400 & 200 & 200 \\
11 & 200 & - & 200 \\
\hline
\end{tabular}

Table 5

Case 1 - expansion plan for GENCO_2.

\begin{tabular}{llll}
\hline Stage & Tech_1 (MW) & Tech_2 $(\mathrm{MW})$ & Tech_3 $(\mathrm{MW})$ \\
\hline 1 & 400 & 300 & - \\
6 & 400 & 300 & 200 \\
8 & 200 & 300 & 200 \\
\hline
\end{tabular}

generated in 2010. As a result of this capacity reduction, all generation agents will invest as much as possible in the three candidate technologies, namely 4000 MW in Tech_1, 2500 MW in Tech_2 and 1600 MW in Tech_3 and the corresponding capacity factors are $0.74,0.55$ and 0.58 . Tables $4-7$ detail the investment plans obtained for GENCO's 1 to 4 and these results show there is a concentration of investments in the first years of each set of 5 years in the horizon (that is, in year 1, 6 and 11) given that in these years we admitted there were new financial resources available for investment Finally, the average electricity market price along the 15 year horizon was $56.8 € / \mathrm{MWh}$.

It should be noticed that obtaining the expansion plans for each GENCO is purely instrumental, given that our main purpose is to estimate the long term evolution of the electricity price. In this sense, we could even have concentrated all generation assets in a single generation company that would have the financial resources resulting from the addition of the resources of the 4 GENCO's. The supply of the demand would still be done building an aggregated supply curve using the segments in which the operation costs of each technology were structured and the price would result from the intersection of this aggregated curve with the demand level. When considering several GENCO's, we wanted to mirror the structure of the Iberian generation system, but for the particular purpose of this paper this analysis could have been simplified. On the other hand, we ran a number of auxiliary simulations considering for instance different values for the financial resources of the GENCO's. The main conclusion that was obtained was that the investment plans would suffer some changes but the average long term electricity price remained almost unchanged which suggests that the mentioned long term average market price of $56.8 € / \mathrm{MWh}$ is fairly insensitive regarding this issue.

\subsection{Case 2 - wind power capacity reduced by $50 \%$ regarding the value of 2010}

In the second simulation we admitted that the wind power installed capacity was reduced to 50\% regarding the value indicated in Table 1, that is, we considered 11,707.5 MW of wind power capacity. In this case the capacity factors of the three candidate technologies got reduced from 0.74 to 0.71 for Tech_1, from 0.55 to 0.53 for Tech_2 and from 0.58 to 0.55 for Tech_3. On the other hand, the average electricity market price got reduced from $56.8 € / \mathrm{MWh}$ obtained in Case 1 to $53.3 € / \mathrm{MWh}$. This is a direct result of considering that part of the demand is supplied by wind parks which means that the liquid demand seen by the remaining generation agents was reduced, thus leading to the shift to the left of the crossing point between the aggregated supply curve with the demand curve. If it is admitted that all the wind power capacity bids on the electricity market, this would mean introducing a new

Table 6

Case 1 - expansion plan for GENCO_3.

\begin{tabular}{llll}
\hline Stage & Tech_1 (MW) & Tech_2 $(\mathrm{MW})$ & Tech_3 $(\mathrm{MW})$ \\
\hline 1 & 400 & 300 & - \\
6 & 400 & - & 200 \\
11 & 400 & 300 & - \\
\hline
\end{tabular}


Table 7

Case 1 - expansion plan for GENCO_4.

\begin{tabular}{llll}
\hline Stage & Tech_1 (MW) & Tech_2 (MW) & Tech_3 (MW) \\
\hline 4 & 400 & 300 & 200 \\
5 & 400 & 200 & 200 \\
\hline
\end{tabular}

generation segment with zero price thus shifting to the right the aggregated supply curve. As a result, the crossing point of this adjusted supply curve with the original demand curve would once again lead to a reduction of the electricity price.

\subsection{Case 3 - wind power capacity existing in 2010 according to Table 1}

This simulation mirrors quite closely the existing situation in the Iberian generation system by 2010 , since all the technologies mentioned in Table 1 were considered, namely 23,415 MW of wind power capacity. As a result of this simulation Tables 8-11 display the expansion plans of GENCO's 1 to 4 and Figs. 4 and 5 display the evolution of the electricity price along the planning horizon and the evolution of the capacity factors of the three candidate technologies. The corresponding average values were as follows: $51.7 € / \mathrm{MWh}$ for the electricity price, 0.69 for the capacity factor of Tech_1, 0.52 for Tech_2 and 0.54 for Tech_3.

Regarding the results obtained in this simulation, the total new installed capacity corresponded to $7600 \mathrm{MW}$, from which $50.0 \%$ is for Tech_1, 28.9\% for Tech_2 and 21.1\% for Tech_3. Tech_1 has the most reduced variable operation cost and its installed capacity was not even larger because the share of each technology was limited to $50 \%$. On the other hand, GENCO_1 was responsible for $30.3 \%$ of the new installed capacity, GENCO_2 for 29.0\%, GENCO_3 for $22.4 \%$ and GENCO_4 for $18.3 \%$. The maximum value of LOLE occurred in year 7 , reaching $0.88 \mathrm{~h} /$ year. Regarding the capacity factors, the graphs for the different technologies displayed in Fig. 5 start at different years because of the construction period that was specified for each of them and also given the year in which the first building decision for each technology was taken. For instance, for Tech_1 it was admitted that the construction period was three years as specified in Section 5.1 and according to Tables $8-11$ the first building decision for Tech_1 was assumed in year 2 by GENCO_1 and GENCO_2. As a result, in Fig. 5 the graph of the capacity factor for Tech_1 starts at year 5 .

\subsection{Case 4 - wind power capacity increased by $25 \%$ regarding the} value of 2010

In this case, the installed capacity in wind parks increases from 23,415 MW in 2010 to 29,269 MW in the starting year of the planning horizon. Using the long term dynamic model to evaluate the evolution of the system, the following main outputs are obtained:

\section{Table 8}

Case 3 - expansion plan for GENCO_1.

\begin{tabular}{llll}
\hline Stage & Tech_1 (MW) & Tech_2 (MW) & Tech_3 (MW) \\
\hline 2 & 400 & - & - \\
3 & 200 & 200 & - \\
5 & 400 & - & - \\
6 & - & 200 & 200 \\
9 & - & 200 & - \\
12 & 200 & - & 200 \\
\hline
\end{tabular}

Table 9

Case 3 - expansion plan for GENCO_2.

\begin{tabular}{llll}
\hline Stage & Tech_1 (MW) & Tech_2 (MW) & Tech_3 (MW) \\
\hline 2 & 400 & - & - \\
3 & - & 200 & - \\
6 & 400 & 200 & 200 \\
10 & - & 200 & - \\
11 & 200 & 200 & 200 \\
12 & - & - & - \\
\hline
\end{tabular}

- the expansion plans of the four GENCO's included $3200 \mathrm{MW}$ of Tech_1, 1900 MW of Tech_2 and 1400 MW of Tech_3;

- this means $6500 \mathrm{MW}$ of new installed capacity along the 15 year horizon. This value represents a reduction of $1100 \mathrm{MW}$ regarding the value obtained in Section 5.4 (reduction of 14.5\%) when considering the wind park installed capacity with the values of 2010;

- as a result of the increase of the wind power installed capacity by $25 \%$, the average electricity market price declined from $56.8 € / \mathrm{MWh}$ in the absence of wind power, to $47.2 € / \mathrm{MWh}$;

- on the other hand, comparing the results obtained in Case 3, existing situation in 2010, with Case 4, we conclude that the extra $5880 \mathrm{MW}$ of wind power capacity generate an average value of 12.88 TWh assuming a capacity factor of 0.25 and, as a result, the average price declined from $51.7 € / \mathrm{MWh}$ in Case 3 to $47.2 € / \mathrm{MWh}$ in this Case, that is a reduction of $4.5 € / \mathrm{MWh}$. This means that a reduction of $1.0 € / \mathrm{MWh}$ in the price required in average 2875 TWh of energy from wind parks. Once again assuming the capacity factor of 0.25 , this means that a reduction of $1.0 € / \mathrm{MWh}$ required an extra wind park capacity of 1310 MW.

5.6. Case 5 - wind power capacity increased by $50 \%$ regarding the value of 2010

Finally, it was simulated a situation in which the wind power installed capacity increased by $50 \%$ regarding the value of 2010 , that is, regarding the value considered in Case 3. This means increasing the wind power installed capacity from 23,415 MW in 2010 to $35122.5 \mathrm{MW}$, that is, an increase of $11707.5 \mathrm{MW}$. As a result of the simulation, the capacity factors of the three candidate technologies got reduced to 0.62 for Tech_1, 0.43 for Tech_2 and 0.48 for Tech_3 and the average electricity market price was reduced to $43.9 € / \mathrm{MWh}$. These results show a reduction of the price by $3.3 € /$ MWh regarding Case 4 and a reduction by $7.8 € /$ MWh regarding the situation that existed in 2010 and reported in Case 3. It is also important to notice that the values of the capacity factors of the three candidate technologies got progressively reduced as the wind power installed capacity increased. This double effect, reduction of the number of operation hours of traditional thermal power stations and reduction of the price they are paid, ultimately means that the revenues of both coal and CCGT stations got strongly reduced in recent years and will likely get reduced further more in the near future. As an example, there are

Table 10

Case 3 - expansion plan for GENCO_3.

\begin{tabular}{llll}
\hline Stage & Tech_1 (MW) & Tech_2 (MW) & Tech_3 (MW) \\
\hline 3 & 400 & - & - \\
4 & - & 200 & 200 \\
6 & 400 & - & - \\
7 & - & 200 & - \\
11 & 200 & - & 200 \\
\hline
\end{tabular}


Table 11

Case 3 - expansion plan for GENCO_4.

\begin{tabular}{llll}
\hline Stage & Tech_1 (MW) & Tech_2 $(\mathrm{MW})$ & Tech_3 $(\mathrm{MW})$ \\
\hline 5 & 400 & 200 & 200 \\
10 & 200 & - & 200 \\
11 & - & 200 & - \\
\hline
\end{tabular}

CCGT stations in the Iberian countries that were commissioned three or four years ago and that are operating 1500-2000 h a year. These reduced capacity factors explain the discussion on the eventual introduction of a capacity term in the remuneration of thermal technologies, given the relevance of these stations for the security of supply of the entire system in view of the volatility of the wind and solar resources. The calibration of such a capacity payment term is discussed in the next Section.

\subsection{Illustration of the calibration of the capacity term to remunerate the installed capacity of thermal stations}

As mentioned in the Introduction, the progressive integration of new stations having neglectable operation costs, namely wind power, associated with pure feed-in tariff schemes brought huge impacts for the remaining power stations in the generation systems. Regarding this issue, the results presented in Sections 5.2-5.6 indicate that:

- Case 1 - if no wind power capacity is considered, the average electricity market price along the 15 year horizon is $56.8 € / \mathrm{MWh}$;

- Case 2 - this value reduces to $53.3 € / M W h$ with a wind power installed capacity of $11707.5 \mathrm{MW}$, that is, half of the value that existed in 2010;

- Case 3 - the average electricity market prices reduces to $51.7 € / M W h$ considering the wind power installed capacity that existed in 2010, that is, 23,415 MW;

- Case 4 - this value reduces to $47.2 € / M W h$ admitting that the wind power installed capacity increases by $25 \%$ regarding the value that existed in 2010 ;

- Case 5 - finally, if the wind power installed capacity increases by $50 \%$ regarding the value of 2010 , the average electricity market price declines to $43.9 € / \mathrm{MWh}$.

This means that all power stations biding in the day-ahead market and being paid its clearing price feel a reduction of their revenues. This reduction is even more severe because the number of hours during which each station is in operation along each year also gets reduced because a larger portion of the demand is actually supplied by wind power. This effect was illustrated by the reduction of the capacity factors of the three candidate technologies when going from Case 1 to Case 5. For instance, for Tech_1 the average

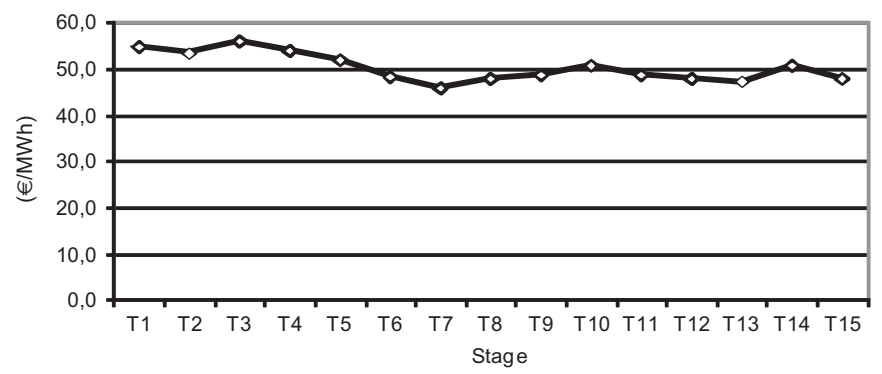

Fig. 4. Case 3 - evolution of the electricity price - wind power installed capacity according to Table 1 .

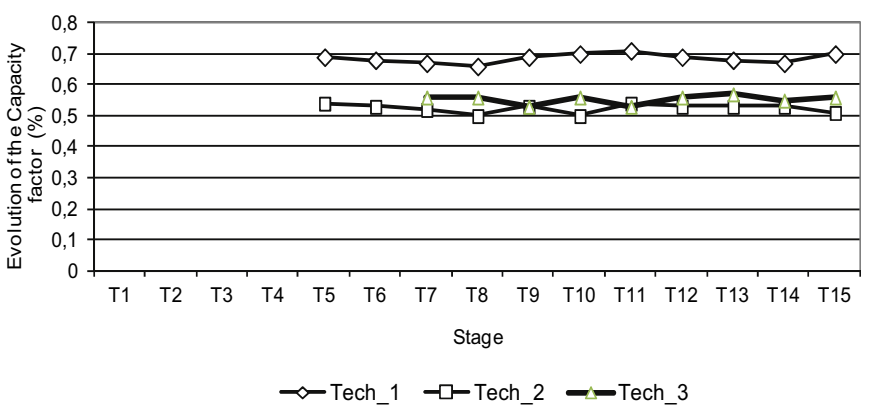

Fig. 5. Case 3 - evolution of the capacity factors - wind power installed capacity according to Table 1.

capacity factor along the 15 year horizon was 0.74 in Case $1,0.69$ in Case 3 and finally 0.62 in Case 5 , that is a reduction of $16.3 \%$.

In a different way, this double effect (reduction of the market price and reduction of the number of operation hours) can also be seen in the decline of the profit estimated for the investments of the 4 GENCO's along the planning horizon. For a particular GENCO, the profit associated with an expansion plan corresponds to the value of the objective function (1) obtained when solving the optimization problem $(1-6)$ to identify the most adequate plan. In percentage, the profit can then be obtained dividing the value of the objective function (1) by the total cost inherent to the associated plan. According to these ideas and using an interest rate of $7 \%$ to refer costs and revenues in (1) to the initial period, the profit of the 4 GENCO's corresponded to $11.3 \%$ of the total costs in Case 3 and then if the wind power installed capacity was increased by $25 \%$, that is if we consider Case 4, this profit reduced to $9.6 \%$.

This effect has been very much discussed in different countries, namely in Portugal, because in several cases thermal stations were built when wind power capacity was not as developed as now and, in any case, this thermal capacity can be required to accommodate variations of wind power injections. Therefore, the introduction of a capacity term in the remuneration of traditional power stations has been discussed in order to prevent shutting down some stations. In line with these concerns, we used the model described in Section 4 to estimate the value that should be adopted for the Pcap term included in (1) so that the profit to be obtained in Case 4 using the same investment plan as in Case 4 would rise to $11.3 \%$. After running the model a number of times, we concluded that a Pcap value of $5.6 € / \mathrm{MW}$ should be adopted. This exercise illustrates one of the advantages of using the model detailed in Section 4, namely by regulatory or state agents, when designing market models and calibrating several parameters inherent to their operation.

In a final exercise, the complete long term simulation was run admitting that $P_{\text {cap }}^{j}$ was set at $10.0 € / \mathrm{MW}$ for every technology $j$ and that the wind power installed capacity was increased by $25 \%$ regarding the value of 2010 , that is, considering Case 4 . The investment plan obtained in this simulation includes $3400 \mathrm{MW}$ of new installed capacity of Tech_1 (more $200 \mathrm{MW}$ than in Case 4), 2100 MW of Tech_2 (more 200 MW than in Case 4) and 1400 MW for Tech_3 (the same value obtained in Case 4). This means that the total new installed capacity rises to $6900 \mathrm{MW}$, that is $400 \mathrm{MW}$ more than in Case 4 but $700 \mathrm{MW}$ less than in Case 3. The slight increase of $400 \mathrm{MW}$ regarding Case 4 is due to the incorporation of the capacity payment turning the investments more interesting. The profit is now $10.8 \%$, a bit smaller than the $11.3 \%$ obtained for Case 3 . This reduction is due to the increase of wind power by $25 \%$ regarding the value used in Case 3 and this effect is not entirely compensated by the $10.0 € / \mathrm{MW}$ capacity payment. The capacity payment term is also the responsible for the increase of the profit regarding the $9.6 \%$ that was originally reported for Case 4. 


\section{Conclusions}

This paper described a long term generation expansion model that includes an optimization module to build generation expansion plans and a dynamic model used to obtain estimates for the evolution of the demand, of the electricity price and of the capacity factors of candidate technologies. This long term model was then used to estimate the evolution of the electricity market price for different shares of wind power installed capacity using realistic data based on the Iberian generation system. The results of these simulations indicate that, assuming the wind power installed capacity that existed by the end of 2010 in the Iberian peninsula, a reduction around $4.5 € / \mathrm{MWh}$ is expected if the wind power capacity increases by $25 \%$, that is, if it increases by $5854 \mathrm{MW}$ regarding the value of 2010 . Assuming a capacity factor of wind parks of 0.25 , this also means that the integration of a block of 12.8 TWh of energy from wind power reduces the price by $4.5 € / \mathrm{MWh}$ or, in other words, each block of $2.8 \mathrm{TWh}$ reduces the price by $1.0 € / \mathrm{MWh}$.

As a result of the increasing penetration of wind power both in Portugal and Spain, the average market price tends to decline and the number of operation hours of traditional thermal technologies also gets reduced. This ultimately means that the profitability of these stations is under pressure and its reduction can induce capacity shortages regarding traditional technologies. This issue should be carefully evaluated given that the EU Directive 2009/72/EC [20] clearly indicates in article 4 that "member states shall ensure the monitoring of security of supply" specifying that "such monitoring shall, in particular, cover the balance of supply and demand on the national market, the level of expected future demand and envisaged additional capacity being planned or under construction". Clearly, if the electricity market prices tend to lower due to an increase of inframarginal volatile technologies, then new investments on traditional technologies tend to reduce and this can risk the security of supply. This corresponds to a source of concern because it is not clear from the Directive who would then assume the responsibility of investing in new capacity. Given the absence of a clearly assigned responsibility on this issue, it seems obvious that market design should be properly studied, that impacts from inframarginal technologies should be anticipated and, if required, capacity markets or adequately calibrated capacity payments should be introduced. In line with these concerns, this paper illustrated the use of the dynamic long term model to help calibrating a capacity term to assign to thermal stations so that their remuneration conditions are improved and these investments become more attractive.

These above aspects illustrate the application of the developed approach both by state or regulatory agencies to investigate the impact of market design options, to conduct sensitivity studies and to calibrate in a more sounded way several parameters that can play an important role in long term investment decisions and ultimately in the security of supply.

\section{Acknowledgement}

The first author would like to thank Fundação para a Ciência e Tecnologia, FCT, that partially funded this research work through the PhD grant no SFRH/BD/29243/2006.

\section{References}

[1] Banovac E, Glavic M, Tesnjak S. Establishing an efficient regulatory mechanism - prerequisite for successful energy activities regulation. Energy International Journal 2009;34(2):178-89.

[2] Banovac E, Gelo T, Simurina J. Analysis of economic characteristics of a tariff system for thermal energy activities. Energy Policy 2007;35(11):5591-600.
[3] Pereira A, Saraiva JT. Generation expansion planning (GEP) - a long term approach using system dynamics and genetic algorithms. Energy International Journal August 2011;36(8):5180-99.

[4] Zhang X. Investment in electricity generation and its determinants. Paris: University of Paris Sud; 2006. Working Paper, France.

[5] International Energy Agency. Power generation investment in electricity markets. International Energy Agency, OECD/IEA; 2003.

[6] Gorenstin BG, Campodonico NM, Costa JP, Pereira MV. Power system expansion planning under uncertainty. IEEE Transactions on Power Systems 1993;8: 129-36.

[7] Sirikum J, Techanitisawad A, Kachitvichyanukul V. A new efficient GA-Benders' decomposition method: for power generation expansion planning with emission controls. IEEE Transactions on Power Systems 2007;22:1092-100.

[8] Antunes CH, Martins AG, Brito IS. A multiple objective mixed integer linear programming model for power generation expansion planning. Energy 2004;29:613-27.

[9] Park J-B, Park Y-M, Won J-R, Lee KY. An improved genetic algorithm for generation expansion planning. IEEE Transactions on Power Systems 2000;15: 916-22.

[10] Yildirim M, Erkan K, Ozturk S. Power generation expansion planning with adaptive simulated annealing genetic algorithm. International Journal of Energy Research 2006;30:1188-99.

[11] Wu F, Yen Z, Hou Y, Ni Y. Applications of AI techniques to generation planning and investment. In: Proceedings of the 2004 IEEE power engineering society general meeting June 2004. Denver, USA.

[12] Park J-B, Kim J-H, Lee KY. Generation expansion planning in a competitive environment using a genetic algorithm. In: . Proceedings of the 2002 IEEE PES summer meeting 2002; vol. 3. p. 1169-72.

[13] Botterud A, Ilic M, Wangensteen I. Optimal investment in power generation under centralised and decentralised decision making. IEEE Transactions on Power Systems 2005;20:254-63.

[14] Forrester J. System dynamics and the lessons of 35 years. In: De Greene KB, editor. The systemic basics of policy making in the 1990s. MIT, USA: Sloan School of Management; April 1991.

[15] Botterud A. Long-term planning in restructured power systems [PhD Thesis]. Trondheim, Norway: Norwegian University of Science and Technology; November 2003.

[16] Olsina F, Garces F, Haubrich H-J. Modelling long-term dynamics of electricity markets. Energy Policy 2006;34:1411-33.

[17] Kadoya T, Sasaki T, Ihara S, Larose E, Sanford M, Graham AK, et al. Utilizing system dynamics modelling to examine impact of deregulation on generation capacity growth. Proceeding of the IEEE 2005;93:2060-9.

[18] Jalal TS, Bodger P. The development of a system dynamics model to evaluate generation expansion in New Zealand. In: Proceedings of AUPEC 2010, Australasian universities power engineering conference December 2010. Christchurch, New Zealand.

[19] Directive 2003/54/EC of the European Parliament and of the Council of 26 June 2003 concerning common rules for the internal market in electricity and repealing Directive 96/92/EC. OJL 15.7.2003;176:37-56.

[20] Directive 2009/72/EC of the European Parliament and of the Council of 13 July 2009 concerning common rules for the internal market in electricity and repealing Directive 2003/54/EC (Text with EEA relevance). OJL 14.8.2009;211: 55-93.

[21] Ministry of Economy and Innovation. Decree-Law no 29/2006 of February 15th. Portugal: Law on the Electricity Sector; 15th February 2006.

[22] Billinton R, Allan R. "Reliability evaluation of power systems". 2nd ed. New York: Plenum Press; 1996. 0-306-45259-6.

[23] Powersim Software AS. Powersim 2.5 user's guide and reference manual. Bergen, Norway: Powersim Press; 1996.

[24] Powersim Software AS. Powersim studio 7 academic. Bergen, Norway: Powersim Software AS; 2006.

[25] International Energy Agency, Nuclear Energy Agency and Organisation for Economic Cooperation and Development, "Projected Costs of Generating Electricity, 2010 Edition", IEA/NEA/OECD, 2011. Available at: http://www.iea. org/Textbase/npsum/ElecCost2010SUM.pdf.

Adelino J. C. Pereira was born in Sanfins, Portugal in 1975. He received his diploma and M.Sc. degrees in Electrical Engineering and Computers from the Faculdade de Engenharia da Universidade do Porto, FEUP, Portugal, in 1998 and 2003. In 1998 he joined the Coimbra Polytechnic Institute (ISEC) where he is currently Adjunct Professor. In July 2010 he concluded his Ph.D. at FEUP with a Thesis on long term generation expansion planning using System Dynamics.

João Tomé Saraiva was born in Porto, Portugal in 1962. In 1987, 1993 and 2002 he got his MSc, PhD, and Agregado degrees in Electrical and Computer Engineering from the Faculdade de Engenharia da Universidade do Porto where he is currently Professor. In 1985 he joined INESC Porto where he was head researcher or collaborated in several projects related with the development of DMS systems, quality in power systems, and tariffs due for the use of transmission and distribution networks. Several of these projects were developed under consultancy contracts with the Portuguese Electricity Regulatory Agency. 